Western University

Scholarship@Western

Human Environments Analysis Lab (HEAL)

$1-2014$

Comparison of hip fracture and osteoporosis medication prescription rates across Canadian provinces

Richard Crilly

Marita Kloseck

Bert M. Chesworth

S. Mequanint

E. Sadowski

See next page for additional authors

Follow this and additional works at: https://ir.lib.uwo.ca/healpub 
Authors

Richard Crilly, Marita Kloseck, Bert M. Chesworth, S. Mequanint, E. Sadowski, and Jason A. Gilliland 


\title{
Comparison of hip fracture and osteoporosis medication prescription rates across Canadian provinces
}

\author{
R. G. Crilly • M. Kloseck • B. Chesworth • S. Mequanint • \\ E. Sadowski • J. Gilliland
}

Received: 2 April 2013 / Accepted: 14 June 2013 / Published online: 2 August 2013

(C) International Osteoporosis Foundation and National Osteoporosis Foundation 2013

\begin{abstract}
Summary The study explores osteoporosis medication prescribing across Canadian provinces and any impact on hip fracture rates. Despite a marked variation in the prescribing of such medication, there is no effect on the hip fracture rate in either gender or any age group, suggesting either poor targeting or lack of efficacy.

Introduction Hip fractures are the most disabling and costly of osteoporotic fractures, and a reduction in the risk of hip fracture is an expectation of osteoporosis medications. In this study, we have compared the use of osteoporosis medication across Canadian provinces with the rate of hip fractures in the same regions.

Methods Three years of hip fracture data (2007-2009 inclusive) were obtained from the Canadian Institute for Health Information for all Canadian provinces excluding Quebec. Population information was obtained from Statistics Canada and medication information from the Brogan Inc. database. Because osteoporosis medication is available daily, weekly,
\end{abstract}

\section{R. G. Crilly $(\bowtie)$}

Division of Geriatric Medicine, Faculty of Medicine, The University of Western Ontario, London, Ontario, Canada

e-mail: richard.crilly@sjhc.london.on.ca

M. Kloseck $\cdot$ B. Chesworth $\cdot$ E. Sadowski

Faculty of Health Sciences, The University of Western Ontario, London, Ontario, Canada

\section{S. Mequanint}

Schulich School of Medicine \& Dentistry, The University of

Western Ontario, London, Ontario, Canada

J. Gilliland

Department of Geography, The University of Western Ontario, London, Ontario, Canada

R. G. Crilly

Division of Geriatric Medicine, Parkwood Hospital,

801 Commissioners Road East, Room A-280, London,

Ontario N6C 5J1, Canada monthly, and yearly, medication prescriptions were converted to "units" of prescribing, so that a once a year infusion represented 365 units, a monthly prescription 30 units, and so forth. Results There is a fourfold difference in prescribing across provinces but no corresponding variation in hip fracture rate. No significant correlation exists between prescribing load and hip fracture rate. This was true for all age groups, both genders, and for both intertrochanteric and subcapital hip fracture. Conclusions We find no association between osteoporosis medication prescribing and hip fracture rate. Possible explanations include insufficient numbers of at-risk patients on treatment, inappropriate targeting, and either lack of efficacy or efficacy limited to only certain subgroups of patients such as those with demonstrable trabecular osteoporosis.

Keywords Hip fracture - Medication · Osteoporosis · Prescription rates

\section{Introduction}

It is an expectation of osteoporosis medications that they reduce non-vertebral fractures as well as vertebral fractures. The various randomized controlled trials conducted have demonstrated that the antiresorptive agents, the mainstay of osteoporosis treatment, can produce a marked reduction in subsequent vertebral fractures and a much more modest reduction in non-vertebral fractures [1]. From the economic perspective, reduction in hip fractures is particularly desirable and has been shown in some studies but not so clearly in others [1]. In most cases, the studies were primarily designed to reduce vertebral fractures. Patients were therefore selected on the basis of spinal osteoporosis, as shown either by low spine density, spinal fractures, or both. In addition to a reduction in vertebral fractures, a reduction in hip fractures was also seen with treatment. Where selection was on the basis of hip cortical bone density, with or without vertebral fractures, a 
reduction in both vertebral and non-vertebral fractures was seen. However, if spinal fractures were not present, the benefits in terms of hip fracture reduction were more variable [2-4]. Generally, the benefit of treating patients with a femoral neck T-score of better than -2.5 is minimal [4].

Approaching the problem from the direction of the hip fracture patient and asking how common osteoporosis actually is in these patients, it is found that although hip bone density predicts future fracture risk, most hip fracture patients do not, in fact, have particularly thin bones compared to their peers $[5,6]$. In our series of hip fracture patients, a minority has a bone density that would be considered low. Thus, only $40 \%$ of women and few men fall below a femoral neck T-score of -2.5 [7]. Similar findings have been reported by Stone et al. in 2003 [8] and Siris et al. in their 2004 study [9] where only $6.4 \%$ fell below this threshold on peripheral bone density measurements. The main problem is that most fractures occur in people who are not at particularly high risk, but because of the great numbers of such people, they contribute most of the fractures. Thus, identification of these people prior to fracture is virtually impossible and indeed the benefit of treating such people is dubious. Even when they have identified themselves by having one hip fracture, prevention of the second hip fracture has proven difficult, presumably because many of the fractured patients are not from the high-risk population [3]. It seems therefore that while such treatment may benefit selected individuals with low bone mass, the impact of this at the population level is less clear and may be insufficient to make a discernable reduction in hip fracture rates.

Studies of the changing rate of hip fracture over the past decades have shown a decline over the years and, while in recent decades there has been a rise in osteoporosis prescription rates, a causal association cannot be presumed. Thus in the study of change in hip fracture rate in Canada over the years from 1985 to 2010, while showing a steady decline over the decades and an increasing rate of decline after 1996, it was felt that this increasing rate of decline began before the use of bisphosphonates was sufficiently widespread to be the cause [10]. Interestingly, a similar finding was seen in the Netherlands with a break in the line at around 1994, while in Spain, a marked increase in prescribing produced no decrease in the hip fracture incidence [11, 12]. In this study, we have explored this issue further. We have compared the use of osteoporosis medication across the provinces of Canada, which varies widely, with the concurrent rate of hip fracture to see if higher prescription rates in certain provinces were associated with lower fracture rates. We have also done this with the intertrochanteric and subcapital fractures separately to see if there is any differential effect on the two fracture types, as there is evidence that the intertrochanteric fracture may be the more trabecular osteoporotic hip fracture for which the antiresorptives might be more effective [13].

\section{Materials and methods}

This study examines osteoporosis medication prescribing and hip fracture rate variation by province (excluding Quebec and the territories) in Canada between 2007 and 2009.

\section{Data sources}

The Canadian Institute for Health Information (CIHI) manages health and healthcare information. CIHI's Discharge Abstract Database (DAD) collects discharge statistics from Canadian healthcare institutions by procedures and diagnoses, including administrative, clinical, and demographic information. The province of Quebec does not contribute to this database and so is not included in our study. Hip fracture data were obtained from CIHI which also provided information on physician numbers across the provinces. Brogan Inc. collates prescription numbers from pharmacies across Canada, including prescriptions funded by private drug plans and the provincial (public) drug plans. The information available includes a measure of the amount of medication dispensed, as prescriptions as such can be written for a variable length of time. The data are collected within a forward sortation area (FSA), this being the geographic region used by Canada Post. And for this study, all FSAs within each province have been amalgamated to obtain prescribing loads per province. The FSA is the region containing the pharmacy dispensing the medication and not that of either the physician or the patient. The assumption is that the prescription is filled close to the home of the patient, which for larger geographic areas and certainly at the provincial level, is almost certainly the case given that healthcare and for the senior population the medication formularies are funded at a provincial level. Population information was obtained from Statistics Canada 2006 census data and is also available by FSA regions.

\section{Measures}

All hospitalization records from 2007 to 2009, in which the most responsible diagnosis was a hip fracture, were obtained from the CIHI DAD and identified using the Canadian Classification of Health Interventions $[C C I]$ and the International Classification of Diseases 10th Revision, Canada [ICD-10-CA]. Hip fractures were identified from the ICD10-CA using diagnosis code S72.0-.2 and from the CCI using diagnosis codes 1VC74LANW, 1VA53LAPMN, and 1GZ31CAND. Total annual hip fractures were calculated for the study period (2007-2009) and stratified by age group, sex, and province (initially 5 -year intervals with aggregation: $55-59,60-64,65-69,70-74,75-79,80-84$, and $\geq 85$ years). It is unclear whether readmission for hip fracture was the result of original hip fracture complications, inter-hospital transfers, or due to a second hip fracture; therefore, all hip 
fracture hospitalizations were counted. Because osteoporosis medication is available daily, weekly, monthly, and yearly, medication dispensing units were converted to days of prescribing, so that a once a year infusion prescription (zoledronic acid) represented 365 days, a prescription for a medication taken monthly (risedronate) represented 30 days of treatment, and so forth. The number of days of prescribing of the osteoporosis medications is summed to provide a measure of the prescribing load for the region and time under consideration. The medications included in the analysis are hormone replacement therapy, risedronate, alendronate, zoledronic acid, didronel, raloxifene, and teriparatide. For the time studied, denosumab was not yet available

The denominator was generated using population data obtained from the 2006 census for each province excluding Quebec. In addition, territories including the Northwest, Yukon, and Nunavut were excluded from this analysis due to their relatively low population base (responsible for .25\% of the overall Canadian population).

\section{Study population}

The database contained a total of 65,659 hip fracture episodes, 18,316 (28\%) in men (average age 78.48 \pm 10.90$)$ and $47,343(72 \%)$ in women (average age 82.08 \pm 9.63$)$. Of the total hip fractures, less than $1 \%$ was disregarded because of missing or incorrect postal code information.

\section{Statistical analysis}

The denominator was derived using provincial census population data from 2006; hip fracture occurrences and prescribing load were aggregated for the years 2007-2009, by province, gender, and age group and then used to calculate the annual unadjusted (crude) fracture rate. Hip fracture rates were standardized per 10,000 person-years and calculated for the population over the age of 54 for each province. Rates were adjusted to the 1991 age structure of the Canadian population using the direct method. Hip fracture rates were analyzed by province for each age group and gender against the osteoporosis medication prescribing load and number of physicians per province. The limited number of data points makes correlation analysis unreliable so the analysis is largely descriptive.

\section{Results}

Figure 1 shows the provinces ranked by prescribing load. There is a substantial difference in prescribing habits across the provinces. This appears to be due to a difference in practice habit and not accessibility to provincial formularies. For example, Alberta and Manitoba have similar formularies (see
Osteoporosis Canada website for details (www.osteoporosis.ca/ index.php/ci id/5521/la_id/1.htm), but quite different rates of prescribing, by a factor of almost 4 . It is not explained by a difference in family physician density (or availability) as this differs little across the provinces, although information about specialists who may have an interest in osteoporosis is not available [14]. Figure 2 also shows the rate of hip fracture across the provinces in the same order for both men and women. There is little difference and clearly no relationship to prescribing load.

Our prescribing data do not provide the age breakdown of the patients for whom the prescriptions are written. It is possible that the impact is on the younger patients and women who may be more likely to be treated. Accordingly we have looked at the hip fracture rate across provinces for different age groups and the separate genders. Again, no relationship between prescribing rate and hip fracture rate emerged. We repeated each of these analyses for the subcapital and intertrochanteric fractures separately but no impact on either was apparent. As an example, Fig. 3 shows proportion of IT fractures in females by province, and again, no effect is apparent. We also noted a reduction in prescribing across the 3 years of the study with a decline of $15.4 \%$ across the 3 years. This is seen in all provinces, but is not associated with any rise in fracture rate.

\section{Discussion}

We have been unable to demonstrate any impact of osteoporosis medication on hip fracture rate across the different provinces in Canada despite a wide variation in prescribing rates. Although our data suffer from some clear deficiencies, such as lack of information about the age and gender of the patients receiving the medication, it is surprising that no impact is even suggested across age groups and either gender. Despite evidence at the individual level that some benefit is to be expected, we are not able to demonstrate this at the population level. Prescribing does not, of course, confirm treatment and the high rate of nonadherence with osteoporosis medication is well known but is likely mostly seen in failure to fill the prescription, so such nonadherence would not affect our results [15].

Targeting of patients for treatment may not be ideal, but as the medications are likely to be prescribed for those with poor bones shown, for example, by a low BMD, some benefit in these patients may be expected. However, we know that most hip fractures occur in patients who do not, on $\mathrm{BMD}$, have a high risk of fracture, and these may not have been targeted for treatment prior to fracture. For example, in our own exploration of hip fracture patients in our locality, 
Fig. 1 The number of osteoporosis medication treatment days per 10,000 population over 55 years across the Canadian provinces for the years 2006-2009. Sources: Brogan Inc. (medication data) and Statistics Canada (population data)

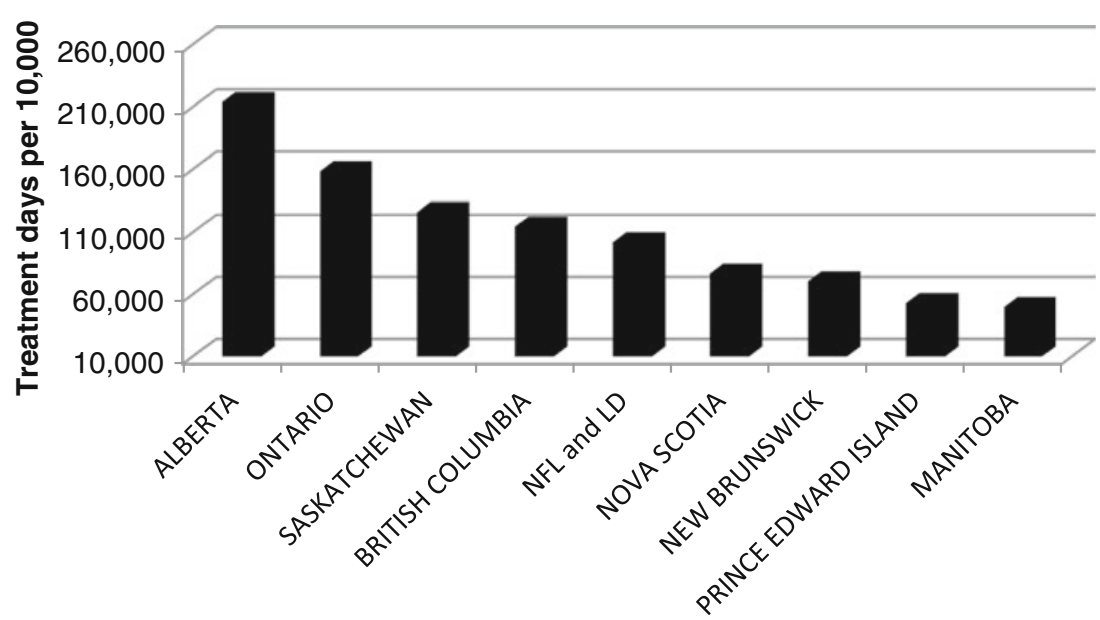

we found only about $30 \%$ of women and very few men fell into the CAROC high-risk zone on the basis of BMD alone [16]. Thus, even with a widespread risk assessment program, only about $25 \%$ of the possible fracture cases might have been treated, with an expected benefit of, at most, a $30 \%$ reduction. Thus, a maximum benefit of a $7.5 \%$ reduction might be the most that could be expected, and, as this would be under ideal conditions of risk assessment, prescribing, and compliance, the benefit may be much less. A recent report [17] explored whether treatment reduces the risk of fracture below that predicted by the FRAX tool [18]. This study suggested an effect only in the highest risk group treated for over 5 years and who show high compliance. Although the authors hypothesize reasons why this does not indicate a failure of efficacy in most treated patients, this would certainly be one and perhaps the simplest explanation. The high-risk patients seem to constitute only $8.5 \%$ of the population being treated and show an observed/predicted ratio of $61 \%$. Again, given that even for high-risk patients' treatment is often not provided, it seems likely that this would make little impact at the population level. We have no information regarding the reasons for the prescribing of the osteoporosis medication. Treated patients may be a mixture of those at risk because of prior fractures with others deemed to be at risk for other reasons. This may all point to the need for better targeting, focusing only on those with clear trabecular osteoporosis who closely resemble those in the original studies. Clearly, a proper ad hoc prospective longitudinal cohort study will be required in order to clearly delineate the patients appropriate for treatment with these medications.

It may be asked if there has been time for the effect to be seen. In most studies, a reduction in hip fracture can be shown within 3 years and sometimes much sooner. The
Fig. 2 Unadjusted crude rates by province per 10,000 person-years of hip fracture by gender (2007 to 2009)

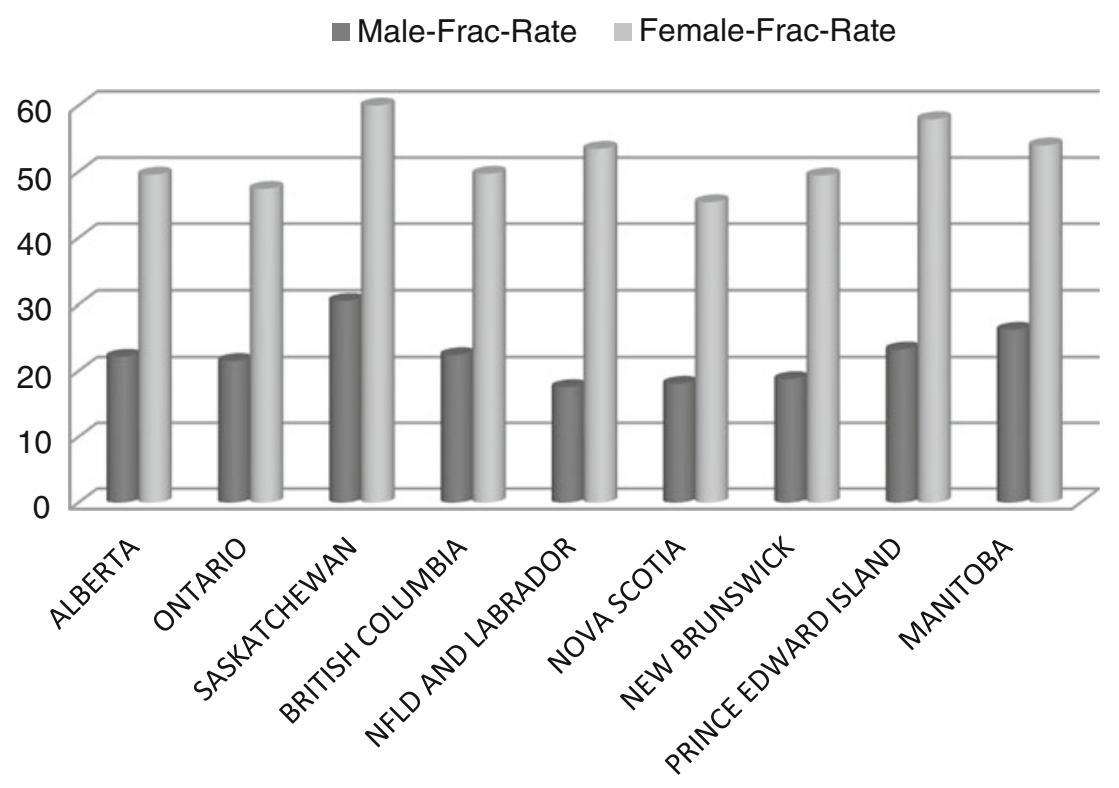


Fig. 3 Unadjusted crude rates by province per 10,000 person-years of female intertrochanteric fracture $(2007$ to 2009)

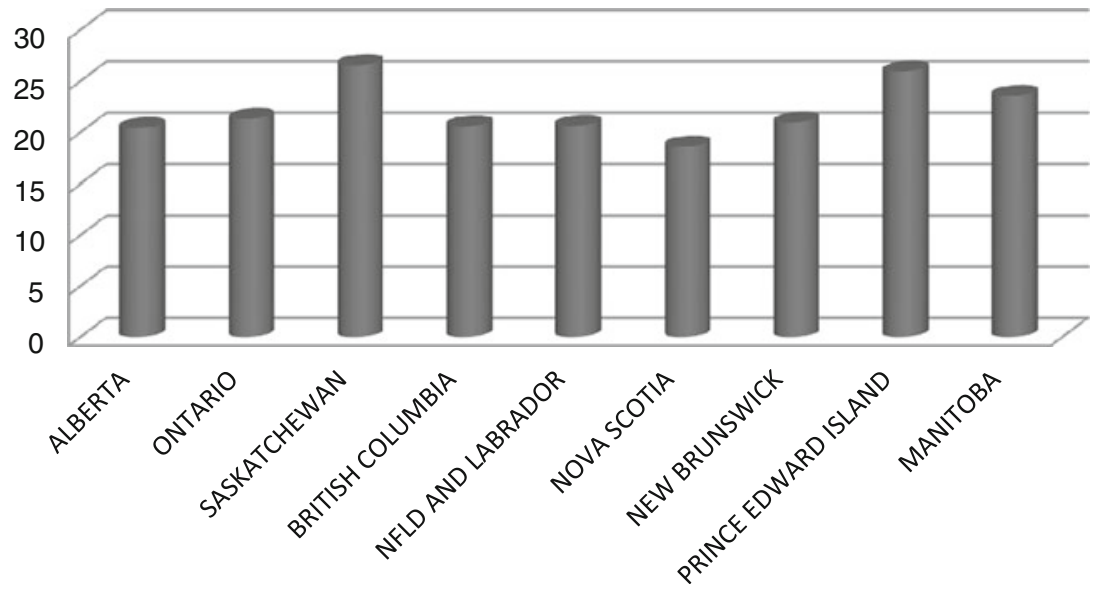

bisphosphonates have been in the market for over 10 years and certainly for more than 3 years prior to our study, so it seems unlikely that this is the explanation.

We have treated all osteoporosis medications as being equal. The vast majority of prescriptions are for the aminobisphosphonates, varying only in frequency (and dose) of administration. Medication may be given daily, weekly, monthly, or yearly and use of "days of treatment" corrects for this disparity. All the aminobisphosphonates have been shown to have similar efficacy at least as far as preventing hip fractures in the mostly osteoporotic patients enrolled in the studies is concerned, so combining in this manner would seem to be justified.

In addition, the rate of prescribing is declining with no obvious effect on hip fracture rate. In this case, however, it may take longer for a decline in prescribing to be reflected in the rise in hip fracture rate.

Lack of efficacy for the most vulnerable segment of the population is another possible explanation. Most hip fractures occur in the elderly who have fallen. Reducing falls may reduce the fracture rate in these people, such as has been shown in the vitamin D studies [19]. We lack evidence of efficacy of osteoporosis medication in the elderly, the most at-risk segment of the population. We know that a fall onto the greater trochanter will produce sufficient force to fracture any hip and this is the type of fall that characterizes the elderly person. About $30 \%$ of those over 65 fall each year and some recurrently [20]. The limited effect of medication on hip bone strength may be insignificant in this situation. Interestingly, the one antiresorptive study to show benefit in terms of hip fracture prevention in patients who were not particularly osteoporotic in terms of trabecular bone status was the denosumab study [21]. This showed a significant $40 \%$ reduction in hip fracture but also a reduced number of falls in the treated group which may have, at least in part, been the mechanism of benefit.
It may be that expanding the use of these medications to a larger segment of the population may not work as their efficacy in low-risk individuals is open to doubt. Additionally, although the concept of fracture risk prediction and prevention is currently fashionable, most of these fractures (about $80 \%$ [1]) are non-vertebral and better predicted by cortical bone status. Therefore, the outcome of the current risk assessment tools $[16,18]$ is that the focus is on the type of bone least responsive to treatment with our current medications.

One remaining possibility is that there are two influences at work: one being the attempt to prevent fractures by treatment and the other being the prescribing of medication in response to the hip fracture. Clearly, these would work in opposite directions and if of equal force may cancel each other out. However, evidence would suggest that the prevention mode is much the greater influence and that the number of people started on treatment because of a hip fracture is small. Several studies have demonstrated the low rate of osteoporosis treatment after a hip fracture [22, 23].

\section{Conclusions}

This study has shown a marked variability in the use of osteoporosis medications across Canadian provinces. Regardless of the cause of this, we have been unable to show any impact on the rate of hip fracture in the different provinces. Additionally, the prescribing appears to be declining and this is again not associated with any change in the fracture rate across our years of study. Possible explanations include inappropriate targeting, insufficient penetration, or lack of efficacy of the medications to impact what appears to be largely a cortical bone problem.

Acknowledgments Our thanks are due to Warner Chilcott Pharmaceuticals for financial support for the study and for facilitating access to the medication data and to Brogan Inc. for the provision of the medication data. 
Conflicts of interest None.

\section{References}

1. Seeman E (2012) Nonvertebral fractures: as good as it gets? International Osteoporosis Foundation overview 12(2). www.iofbonehealth. org/volume-12-issue-2. Accessed 30 January 2013

2. McClung MR, Geusens P, Miller PD, Zippel H, Bensen WG, Roux C, Adami S, Fogelman I, Diamond T, Eastell R, Meunier J, Reginster JY (2001) Effect of risedronate on the risk of hip fracture in elderly women. N Engl J Med 334(5):333-340

3. Lyles K, Colón-Emeric CS, Magaziner JS, Adachi JD, Pieper CF, Mautalen C, Hyldstrup L, Recknor C, Nordsletten L, Moore KA, Lavecchia C, Zhang J, Mesenbrink P, Hodgson PK, Abrams K, Orloff JJ, Horowitz Z, Eriksen EF, Boonen S (2007) Zoledronic acid and clinical fractures and mortality after hip fracture. N Engl J Med 357(18):1799-1809

4. Cummings SR, Black DM, Thompson DE, Applegate WB, BarrettConnor E, Musliner TA, Palermo L, Prineas R, Rubin SM, Scott JC, Vogt T, Wallace R, Yates AJ, LaCroix AZ (1998) Effect of alendronate on risk of fracture in women with low bone density but without vertebral fractures. JAMA 280(24):2077-2082

5. Cummings SR, Black DM, Nevitt MC, Browner W, Cauley J, Ensrud K, Genant HK, Palermo L, Scott J, Vogt TM (1993) Bone density at various sites for prediction of hip fractures. The Study of Osteoporotic Fractures Research Group. Lancet 342(8837):72-75

6. Cummings SR (1985) Are patients with hip fractures more osteoporotic? Review of the evidence. Am J Med 78(3):487-494

7. Crilly RG, Cox L (2013) A comparison of bone density and bone morphology in those presenting with hip fractures, spinal fractures or a combination of the two. BMC Musculoskelet Disord 14:68. doi:10.1186/1471-2474-14-68

8. Stone KL, Seeley DG, Lui LY, Cauley JA, Ensrud K, Browner WS, Nevitt MC, Cummings SR (2003) BMC at multiple sites and risk of fracture of multiple types: long-term results from the Study of Osteoporotic Fractures. J Bone Miner Res 18(11):1947-1954

9. Siris ES, Chen Y-T, Abbott TA, Barrett-Connor E, Miller PD, Wehren LE, Berger ML (2004) Bone mineral density thresholds for pharmacological intervention to prevent fractures. Arch Intern Med 164(1):1108-1112

10. Leslie WD, O’Donnell S, Jean S, Legacé C, Walsh P, Bancej C, Morin S, Hanley DA, Papaioannou A (2009) Trends in hip fracture rates in Canada. JAMA 302(8):883-889
11. Hartholt KA, Oudshoorn C, Zielinski SM, Burgers PT, Panneman MJ, van Beeck EF, Patka P (2011) The epidemic of hip fractures: are we on the right track? PLoS One 6(7):e22227. doi:10.1371/journal. pone. 0022227

12. Guerra-García MM, Rodríguez-Fernández JB, Puga-Sarmiento E, Charle-Crespo MÁ, Gomes-Carvalho CS, Prejigueiro-Santás A (2011) Incidence of hip fractures due to osteoporosis in relation to the prescription of drugs for their prevention and treatment in Galicia, Spain. Aten Primaria 43(2):82-88. doi:10.1016/j.aprim. 2010.04.010, Epub 2010 Jun 15. Spanish

13. Nakamura N, Kyou T, Takaoka K, Ohzono K, Ono K (1992) Bone mineral density in the proximal femur and hip fracture type in the elderly. J Bone Miner Res 7(7):755-759

14. Osteoporosis Canada (2012) www.osteoporosis.ca/index.php/ci id/5521/la_id/1.htm. Accessed 12 February 2013

15. Jones TM, Petrella RJ, Crilly R (2008) Determinants of persistence with weekly bisphosphonates in patients with osteoporosis. J Rheumatol 35(9):1865-1873

16. Papaioannou A, Morin S, Cheung AM, Atkinson S, Brown JP, Feldman S, Hanley DA, Hodsman A, Jamal SA, Kaiser SM, Kvern B, Siminoski K, Leslie WD (2010) clinical practice guidelines for the diagnosis and management of osteoporosis in Canada: summary. CMAJ. doi:10.1503/cmaj.100771

17. Leslie WD, Lix LM, Johansson H, Oden A, McCloskey E, Kanis JA (2012) Does osteoporosis therapy invalidate FRAX ${ }^{\circledR}$ for fracture prediction? J Bone Miner Res 27:1243-1251

18. FRAX WHO Fracture Risk Assessment Tool http://www.shef.ac. uk/FRAX/tool.j Accessed 12 February 2013

19. Bischoff-Ferrari HA, Dawson-Hughes B, Willett WC, Staehelin HB, Bazemore MG, Zee RY, Wong JB (2004) Effect of vitamin D on falls. A meta-analysis. JAMA 291:1999-2006

20. O'Loughlin JL, Robitaille Y, Boivin JF, Suissa S (1993) Incidence of and risk factors for falls and injurious falls among the community-dwelling elderly. Am J Epidemiol 137:342-352

21. Cummings SR, San Martin J, McClung MR, Siris E et al (2009) Denosumab for prevention of fractures in Postmenopausal women with osteoporosis. N Engl J Med 361:756-765

22. Rabenda V, Vanoverloop J, Fabri V, Mertens R, Sumkay F, Vannecke C, Deswaef A, Verpooten GA, Reginster JY (2008) Low incidence of anti-osteoporosis treatment after hip fracture. Bone Joint Surg Am 90(10):2142-2148

23. Jennings LA, Auerbach AD, Maselli J, Pekow PS, Lindenauer PK, Lee SJ (2010) Missed opportunities for osteoporosis treatment in patients hospitalized for hip fracture. J Am Geriatr Soc 58:650-657 